\title{
Simulation of the effect of maize porridge fortified with grain amaranth or micronutrient powder containing NaFeEDTA on iron intake and status in Kenyan children
}

\author{
Catherine W Macharia-Mutie ${ }^{1,2, *}$, Agnes M Omusundi ${ }^{1}$, John M Mwai ${ }^{3}$, \\ Alice $M$ Mwangi $^{3}$ and Inge D Brouwer ${ }^{1}$ \\ 'Division of Human Nutrition, Wageningen University, PO Box 8129, 6700 EV Wageningen, The Netherlands: \\ ${ }^{2}$ Directorate of Research Management and Development, Ministry of Higher Education Science and Technology, \\ Nairobi, Kenya: ${ }^{3}$ Applied Nutrition Program, University of Nairobi, Nairobi, Kenya
}

Submitted 23 May 2012: Final revision received 22 October 2012: Accepted 26 October 2012: First published online 6 December 2012

\begin{abstract}
Objective: Simulating the probable impact of grain amaranth and highly absorbable, low-Fe micronutrient powder (MNP) on Fe status in a potential target population is an essential step in choosing and developing an appropriate actual intervention.

Design: We simulated the potential effect of fortifying maize porridge with grain amaranth or MNP on the prevalence of inadequate Fe intake and Fe deficiency using data from two cross-sectional surveys. In the first survey (2008), dietary intake data were collected by two $24 \mathrm{~h}$ recalls $(n$ 197). Biochemical data $(n 70)$ were collected in the second survey (2010). A simulation with daily consumption for $80 \mathrm{~d}$ of non-fortified maize porridge ( $60 \mathrm{~g}$ of maize flour), amaranth-enriched porridge ( $80 \mathrm{~g}$ of grain amaranth-maize flour, 70:30 ratio) or maize porridge fortified with MNP (2.5 mg Fe as NaFeEDTA) was done.

Setting: Mwingi District, Kenya.

Subjects: Pre-school children aged 12-23 months.

Results: Prevalence of anaemia, Fe deficiency and Fe-deficiency anaemia was $49 \%, 46 \%$ and $24 \%$, respectively. Consumption of non-fortified, amaranth-enriched and MNP-fortified maize porridge was estimated to provide a median daily Fe intake of $8.6 \mathrm{mg}, 17.5 \mathrm{mg}$ and $11.1 \mathrm{mg}$, respectively. The prevalence of inadequate $\mathrm{Fe}$ intake was reduced to $35 \%$ in the amaranth-enriched porridge group and $45 \%$ in the MNP-fortified porridge group, while ferritin concentration was increased in both (by $1.82(95 \%$ CI $1.42,2 \cdot 34) \mu \mathrm{g} / \mathrm{l}$ and 1.80 (95\% CI 1.40 , 2.31) $\mu \mathrm{g} / \mathrm{l}$, respectively; $P<0 \cdot 005)$ compared with the non-fortified maize porridge group, resulting in a decreased prevalence of Fe deficiency (27\%) in the two fortification groups.

Conclusions: Addition of grain amaranth or low-Fe MNP to maize-based porridge has potential to improve Fe intake and status in pre-school children.
\end{abstract}

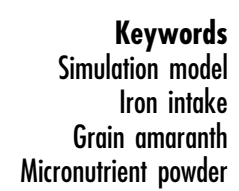

Iron deficiency (ID) and anaemia are a global public health problem, especially in sub-Saharan Africa, impacting the health and cognitive potential of young children $^{(1-3)}$. Global estimates show that the highest prevalence of anaemia (47.4\%) is among children under 5 years of age, with the prevalence rising to $64.6 \%$ in Africa $^{(1,2)}$. The 1999 Kenya national micronutrients survey estimated that $70 \%$ of children under the age of 5 years were likely to be anaemic, while nearly half $(43 \cdot 2 \%)$ had $\mathrm{ID}^{(4)}$. High prevalence of inadequate dietary intake, an immediate determinant of micronutrient deficiencies, of up to $77 \%$ has been reported among Kenyan children ${ }^{(5,6)}$. Plant foods have been found to be the major source of energy, of which cereals contribute $\sim 62-68 \%$ to total daily energy intake, among Kenyan infants and preschool children ${ }^{(6-9)}$. In addition, maize in the form of soft or stiff maize porridge has been shown to be the major complementary food for children aged 12-23 months, contributing over $50 \%$ of $\mathrm{Fe}$ intake ${ }^{(7,9)}$.

Food-based approaches, including home fortification with low doses of highly absorbable, low-Fe micronutrient powders (MNP) or dietary diversification, may enhance the probability of adequate nutrient intake ${ }^{(1,10)}$ among children. Consumption of MNP together with food has been found to improve Fe status in children within short intervention periods ${ }^{(11-13)}$. Less studied but widely 
consumed wholegrain cereals such as grain amaranth (Amaranthus spp.) may have the potential to improve Fe status among children in areas of chronic food insecurity. Grain amaranth is reported to have two to four times more Fe than wheat, high-quality proteins that are easily digested compared with other cereals and to be a drought-resistant fast-maturing crop able to survive in semi-arid areas $^{(14,15)}$.

Simulating the probable impact of strategies on the potential target population is an essential step in the choice and development of the appropriate actual intervention. Previous studies have simulated intervention effects of $\mathrm{Zn}$ and Fe bio-fortification as well as increased use of animal-source foods to reduce the prevalence of inadequate $\mathrm{Zn}$ and $\mathrm{Fe}$ intakes among women and young children $^{(6,16,17)}$, but none has attempted to estimate the possible effect on Fe status particularly while using plant foods or MNP. The objective of the present study therefore was to use data on food consumption patterns of 12-23-month-old Kenyan children to simulate the potential effect of enriching maize porridge with grain amaranth flour or MNP on the adequacy of Fe intake and the prevalence of ID.

\section{Methods}

\section{Study design and participants}

Two cross-sectional surveys were carried out in Migwani Division of Mwingi District, Kenya, purposively selected as it falls in a semi-arid area that experiences food shortage for most of the year. In both surveys, multistage sampling was used. Two locations within Migwani Division, namely Migwani and Nzauni, were randomly chosen for the purpose of these studies. The sampling frame consisted of households with children below 5 years of age, but only one child per household within the defined age was randomly selected so as to get a more representative sample population. Households were selected using the random walk method until the desired sample size was achieved $^{(18)}$. Informed verbal and written consent was obtained from the principal caregiver/parent. Both studies were approved as part of a larger study by the Kenyatta National Hospital/University of Nairobi Ethical Review Committee and the Ministry of Higher Education, Science and Technology in Kenya. A quantitative food consumption survey was carried out in March 2008 involving 197 children aged 12-23 months. Their characteristics have been described elsewhere ${ }^{(7)}$. Data from that survey were used to simulate the effect of fortification of maize porridge with grain amaranth or MNP on Fe intake. A second survey was done in January 2010 including 263 children aged 12-59 months. From a subsample ( $n$ 70; aged 12-23 months) it was estimated whether the simulated effect of the intervention on Fe intake as found in the first survey would translate into a reduction of ID prevalence in this age group assuming a similar food consumption pattern for children in the two surveys.

\section{Antbropometry}

Weight measurements were taken with either a Salter spring scale (UNICEF) or a digital bathroom scale (Ashton Meyers ${ }^{\circledR}$ model no. 7752, Dubai, United Arab Emirates). The bathroom scale was only used if a child refused to put on the provided weighing pants or could not fit in them. Weight was measured to the nearest $0 \cdot 1 \mathrm{~kg}$. The children were in minimum clothing which was not corrected for during analysis. Standing height $(>2$ years) or recumbent length ( $<2$ years) was measured to the nearest $0 \cdot 1 \mathrm{~cm}$ using height/length wooden boards. All measurements were done twice. If the variation between the two measurements was more than $0.5 \mathrm{~kg}$ or $1.0 \mathrm{~cm}$ for weight or height/length, respectively, the measurements were done a third time ${ }^{(19)}$ and the mean value calculated. Age was calculated from the birth date reported on clinic cards or, in rare cases, on parent's/principal caregiver's recall.

\section{Blood collection and analysis}

Non-fasting venous blood samples $(5 \mathrm{ml})$ were collected from children by venepuncture and divided into two portions. The first portion sample series were stored in EDTA tubes (Becton-Dickinson ${ }^{\circledR}$, Temse, Belgium) for determination of $\mathrm{Hb}$ concentration, while the second portion sample series were stored in plain tubes without anticoagulant for serum separation. The samples were stored in cool boxes and transported to Migwani Hospital. Hb concentration was determined using a KX-21 haematological analyser (Sysmex Corporation, Kobe, Japan). Separation was done within $6 \mathrm{~h}$ and serum was transferred into sterile cryovials, flushed with pure white spot $\mathrm{N}_{2}$ gas and thereafter stored in liquid $\mathrm{N}_{2}$ before further analysis in Nairobi. Serum ferritin (SF) was analysed using enzyme-linked fluorescent assay with a Mini-VIDAS ${ }^{\circledR}$ Immunoanalyser (Biomeriux SA, Johannesburg, South Africa), while C-reactive protein (CRP) was analysed using a NycoCard ${ }^{\circledR}$ Reader II at the Centre for Public Health Research, Nairobi. Serum transferrin receptor (sTfR) was analysed with a Cobas Integra ${ }^{\circledR}$ analyser (Roche Diagnostics, Mannheim, Germany) at the Pathologists Lancet Kenya Ltd, Nairobi. Certified reference kits/cell controls were used for precision determination during analysis. All samples were measured once and the CV was $<10 \%$.

\section{Dietary intake}

Food consumption was measured using repeated $24 \mathrm{~h}$ recall on two non-consecutive days as described previously $^{(7,18)}$. The observed intakes were adjusted for day-to-day variation using the US Institute of Medicine adjustment procedure to obtain the estimated usual intake for each individual ${ }^{(20)}$. The full probability approach was used to estimate the prevalence of Fe intake inadequacy 
assuming an average bioavailability of $5 \%{ }^{(21)}$. The total amount of $\mathrm{Fe}$ absorbed after the simulated intervention was obtained by adding the total estimated absorbable Fe from the different treatments to that absorbed from the usual intake. The total amount of actual and simulated absorbable Fe per child was categorized into probabilities of inadequacy ranging from 0 to 1 , where 0 was assigned to absorbed Fe that fell above the $97 \cdot 5$ th percentile of requirements and 1 was assigned to absorbed Fe that fell below the $2 \cdot 5$ th percentile of requirements ${ }^{(21)}$. The average of the prevalence of inadequacy in the different categories gave an estimate of the total prevalence of inadequacy in the population. Energy requirement was estimated at $3766 \mathrm{~kJ} / \mathrm{d}(900 \mathrm{kcal} / \mathrm{d})$, the average requirement of a girl or boy aged 1-2 years at moderate physical activity $^{(22)}$.

To describe the dietary pattern, each individual's dietary diversity score (DDS) was calculated using the first-day recall data and a $1 \mathrm{~d}$ simple qualitative FFQ asking information on the number of meals and types of foods/ingredients in each meal from the second survey. All ingredients mentioned in the $24 \mathrm{~h}$ recall or in the qualitative FFQ were assigned into eleven food groups: (i) cereals roots and tubers; (ii) legumes and nuts; (iii) vitamin A-rich fruits and vegetables; (iv) dark green leafy vegetables; (v) other fruits and vegetables; (vi) dairy; (vii) meat, poultry and fish; (viii) eggs; (ix) organ meats; (x) condiments; and (xi) fats and oils. We did not include the fats and oil group when awarding the scores, or the condiments, since our focus was on Fe intake ${ }^{(23)}$. If a food from a certain food group was consumed, this food group received a score of 1 ; otherwise a score of 0 was given if no food from that group was consumed. To calculate individual DDS, the scores for each food group were summed; hence the minimum score was ' 0 ' and the maximum score was ' 9 '. The children were further classified into DDS tertiles: low ( $\leq 3$ food groups), medium ( $4-5$ food groups) and high dietary diversity ( $\geq 6$ food groups) ${ }^{(23)}$.

\section{Simulation}

A simulation model using the deterministic approach was developed to estimate the expected change in the prevalence of Fe intake inadequacy. It was based on three types of porridges: (i) plain maize porridge with $60 \mathrm{~g}$ of maize flour; (ii) amaranth-maize porridge with $80 \mathrm{~g}$ of flour at the ratio of $70 \%$ grain amaranth $(56 \mathrm{~g})$ and $30 \%$ maize ( $24 \mathrm{~g}$ ); and (iii) maize porridge ( $60 \mathrm{~g}$ of maize flour) with added $1 \mathrm{~g}$ of MNP containing vitamin A $(100 \mu \mathrm{g}$ retinol equivalents), vitamin D $(5 \mu \mathrm{g})$, vitamin $\mathrm{E}(5 \mathrm{mg}$ tocopherol equivalents), phylloquinone $(30 \mu \mathrm{g})$, thiamin $(0.5 \mathrm{mg})$, riboflavin $(0.5 \mathrm{mg})$, pyridoxine $(0.5 \mathrm{mg})$, folic acid $(90 \mu \mathrm{g})$, niacin $(6 \mathrm{mg})$, vitamin $\mathrm{B}_{12}(0.9 \mu \mathrm{g})$, vitamin $\mathrm{C}$ (60 mg), Fe (2.5 mg as NaFeEDTA), Zn ( $2.5 \mathrm{mg})$, Se (17 $\mu \mathrm{g})$, $\mathrm{Cu}(0 \cdot 34 \mu \mathrm{g})$ and iodine $(30 \mu \mathrm{g})^{(24,25)}$. The amount of flour required to make the plain maize porridge was lower as the consistency was found to be thicker than for a similar amount of porridge made from grain amaranth and maize at 70:30 ratio ${ }^{(26)}$. We also desired to give as much Fe from grain amaranth as possible, and a previous sensory study showed a preference for porridges with a lower amount of amaranth flour but no significant difference between 50:50 and 70:30 amaranth-maize mixtures ${ }^{(26)}$. It was assumed that these porridges would be added to the children's diet as an extra meal, as previously estimated energy and $\mathrm{Fe}$ intakes for children in the area showed that nutrient adequacy was $<70 \%$ for both energy and Fe requirements ${ }^{(7)}$.

Simulations of the effect of the intervention on Fe intake were made using data from the first survey. Assumptions made included: (i) wet weight $\mathrm{Fe}$ content of maize is $0 \cdot 061 \mathrm{~g} / \mathrm{kg}$ and of grain amaranth is $0 \cdot 20 \mathrm{~g} / \mathrm{kg}$ based on own analysis of the flours (CW Macharia-Mutie, AM Mwangi and ID Brouwer, unpublished results); (ii) bioavailability of Fe from maize flour in all of the porridges is $4 \%{ }^{(27)}$, bioavailability of the $70 \%$ grain amaranth flour in the amaranth-maize porridge is $3 \%{ }^{(15)}$ and bioavailability of the $2.5 \mathrm{mg}$ Fe in the form of NaFeEDTA is $7 \%^{(28)}$; and (iii) the intervention would last for 80 d, i.e. 16 weeks of feeding at $5 \mathrm{~d} /$ week, as treatment effects may be achieved within this time frame and an even shorter period for $\mathrm{MNP}^{(29)}$. We also assumed that the baseline usual Fe intake for children was the median intake $(4.9 \mathrm{mg} / \mathrm{d})$ obtained from the food consumption data. The additional absorbable Fe obtained by simulating the different treatments was added to the assumed median usual absorbed Fe intake of $0.24 \mathrm{mg} / \mathrm{d}$ calculated from an overall Fe bioavailability of $5 \%$ based on the regular diet containing enhancers such as ascorbic acid and animal-source foods but in limited amounts, a characteristic found in our previous study ${ }^{(1,7)}$. The prevalence of inadequate Fe intake was then estimated for the three groups using the full probability approach as described earlier ${ }^{(21)}$.

Results of the second survey were used to estimate the expected change in prevalence of ID, SF concentration and body Fe stores. Assumptions made include: (i) total median Fe requirement for growth and basal losses of $0.46 \mathrm{mg} / \mathrm{d}$ for a child aged $1-3$ years weighing $13.3 \mathrm{~kg}$, equivalent to $34.6 \mu \mathrm{g} \mathrm{Fe} / \mathrm{kg}$ body weight per $\mathrm{d}^{(30)}$; and (ii) absorbed Fe in excess of the total median requirement for growth and basal losses would be used in the formation of Fe stores at the end of the $80 \mathrm{~d}$ intervention. Total Fe stores after the intervention were calculated assuming that the amaranth-enriched and MNP-fortified porridge will provide an extra 13.5 and $8.3 \mu \mathrm{g} \mathrm{Fe} / \mathrm{kg}$ body weight per d, respectively, while the non-fortified maize porridge group would have a deficit of $5.3 \mu \mathrm{g} \mathrm{Fe} / \mathrm{kg}$ body weight per $\mathrm{d}$. These values were obtained after deducting the daily median requirement of $34 \cdot 6 \mu \mathrm{g} \mathrm{Fe} / \mathrm{kg}$ body weight per $\mathrm{d}$. Further, a linear relationship between log SF and Fe stores per unit body weight was assumed. The equation: $Y=9380 X-11260$, where $Y(\mu \mathrm{g} \mathrm{Fe} / \mathrm{kg}$ body weight $)$ is the 
total body Fe calculated after the intervention and $X$ is $\log$ SF, as described by Hallberg et al. ${ }^{(31)}$, was used to estimate the log SF for every child assuming that he/she received the different treatments. The exponential of $\log$ SF was assumed to be the extra SF formed or deficit at the end of the $80 \mathrm{~d}$ intervention. These values were then added to the original SF values which had been corrected for acute inflammation (see next section) to give the final SF value for the three different treatments.

\section{Data analysis}

Anaemia was defined as $\mathrm{Hb}<110 \mathrm{~g} / \mathrm{l}$. ID was defined as $\mathrm{SF}<12 \mu \mathrm{g} / \mathrm{l}^{(32)}$ or $\mathrm{sTfR}>8.3 \mathrm{mg} / \mathrm{l}$ (Roche kit specific). Body Fe content was calculated using the formula ${ }^{(33)}$ : body $\mathrm{Fe}(\mathrm{mg} / \mathrm{kg})=-[\log (\mathrm{sTfR} / \mathrm{SF})-2 \cdot 8229] / 0 \cdot 1207$. This was after recalculation of Roche kit sTfR values with the regression equation: $\mathrm{STfR}=1.5 \times$ Roche kit values $+0 \cdot 35$, to transform them to ELISA assay values ${ }^{(34)}$. To adjust SF concentration for those children with elevated CRP $(>5 \mathrm{mg} / \mathrm{l})$, a correction factor $(0 \cdot 67)$ was used to yield an adjusted value representative of a child without acute inflammation $^{(35)}$.

Weight-for-height $Z$-score (WHZ), weight-for-age $Z$-score (WAZ) and height-for-age Z-score (HAZ) were calculated with ANTHRO version $3 \cdot 2 \cdot 2$, using the 2006 WHO growth standards. Stunting, underweight or wasting respectively was defined as WHZ, WAZ or HAZ $<-2^{(36)}$. Statistical analyses were done using the SPSS statistical software package version $16 \cdot 0$ and Microsoft ${ }^{\circledR}$ Excel 2003. Univariate analysis with planned contrasts was done to estimate treatment effects on SF and body Fe concentration relative to the maize porridge-only group after simulated intervention. The level of significance was set at $P<0 \cdot 05$.

\section{Results}

Mean energy intake for the 197 children who participated in the first survey was $2902 \mathrm{~kJ} / \mathrm{d}$, with $88 \%$ of the children having an intake below the daily energy requirements for children aged $1-2$ years (Table 1 ). Maize contributed more than half $(57 \%)$ of the $\mathrm{Fe}$ intake and a third of the energy and protein intakes in the children's diet.
Nearly half (48\%) of children had a low DDS and only $2 \%$ had a high DDS (data not shown).

More than half $(60 \%)$ of the children who participated in the second survey were stunted, $49 \%$ were anaemic and $50 \%$ had a low DDS (Table 2). The cumulative prevalence of ID (45.7\%) as indicated by SF and STfR was indicative of a high prevalence of Fe depletion. Only half of the children with anaemia had Fe-deficiency anaemia (24.3\%). The simulations estimated that amaranth-enriched and MNP-fortified porridges would provide extra body Fe stores of 0.013 and $0.008 \mathrm{mg} \mathrm{Fe} / \mathrm{kg}$ body weight per $\mathrm{d}$, respectively, while the non-fortified maize porridge group would have a deficit of $0.005 \mathrm{mg} \mathrm{Fe} / \mathrm{kg}$ body weight per $\mathrm{d}$ compared with the absolute median requirement for a child aged 12-23 months (Table 3). The extra $\mathrm{Fe}$ would cause a modest increase of $\mathrm{Fe}$ stores by 1.1 and $0.7 \mathrm{mg} \mathrm{Fe} / \mathrm{kg}$ body weight in the amaranthenriched and MNP-fortified porridge group, respectively, after the intervention. Simulated SF concentration increased by $\sim 5 \mu \mathrm{g} / 1$ in the amaranth-enriched and MNP-fortified porridge groups compared with baseline. The prevalence of inadequate $\mathrm{Fe}$ intake was estimated to decrease to $35 \%$ and $45 \%$ after an assumed consumption of amaranthenriched maize porridge or maize porridge with MNP, respectively, translating into over $50 \%$ reduction. Based on the second survey the increased estimated SF in the amaranth and MNP groups reduced the prevalence of ID in the two groups to $27 \%$, but not in the maize porridge-only group. Consumption of amaranth-enriched maize porridge or MNP-fortified maize porridge was estimated to cause a similar and significant improvement in SF concentration (1.82 (95\% CI 1.42, 2.34) $\mu \mathrm{g} / \mathrm{l}$ and $1 \cdot 80$ (95\% CI 1·40, 2.31) $\mu \mathrm{g} / \mathrm{l}$, respectively) compared with the maize porridge-only group $(P<0 \cdot 005)$.

\section{Discussion}

Simulated results showed that enriching maize porridge with grain amaranth or MNP may comparably reduce the prevalence of inadequate Fe intake and ID among children aged 12-23 months in Mwingi District, Kenya. Giving extra maize porridge only will improve energy intake but not

Table 1 Adjusted usual dietary intaket distributions among children ( $n$ 197) aged 12-23 months in Mwingi District, Kenya, 2008 (first survey)

\begin{tabular}{lcccccc}
\hline & \multicolumn{9}{c}{ Nutrient intake } \\
\cline { 2 - 6 } & Mean & SD & Median & P25 & P75 & Contribution of maize \\
to nutrient (\%)
\end{tabular}

P25, 25th percentile; P75, 75th percentile.

tThe estimated nutrient intakes do not account for breast milk intakes as they were not measured. 
Table 2 Characteristics of children ( $n$ 70) aged 12-23 months in Mwingi District, Kenya, 2010 (second survey)

\begin{tabular}{|c|c|c|c|c|}
\hline & $n$ & Frequency (\%) & Mean & SD \\
\hline \multicolumn{5}{|l|}{ Demography } \\
\hline \multicolumn{5}{|l|}{ Sex } \\
\hline Male & 32 & $45 \cdot 7$ & & \\
\hline \multicolumn{5}{|l|}{ Anthropometry } \\
\hline WAZ & 70 & & $-1 \cdot 6$ & $1 \cdot 1$ \\
\hline HAZ & 70 & & $-2 \cdot 1$ & $1 \cdot 1$ \\
\hline WHZ & 70 & & $-0 \cdot 8$ & $1 \cdot 2$ \\
\hline Underweightt & 24 & $34 \cdot 3$ & & \\
\hline Stuntedt & 42 & $60 \cdot 0$ & & \\
\hline Wastedt & 13 & $18 \cdot 5$ & & \\
\hline \multicolumn{5}{|l|}{ Dietary diversity score } \\
\hline Low ( $\leq 3$ food groups) & 35 & $50 \cdot 0$ & & \\
\hline Medium (4-5 food groups) & 34 & $48 \cdot 6$ & & \\
\hline High ( $\geq 6$ food groups) & 1 & $1 \cdot 4$ & & \\
\hline \multicolumn{5}{|l|}{ Biochemical characteristics } \\
\hline $\mathrm{Hb}(\mathrm{g} / \mathrm{l})$ & 70 & & $108 \cdot 9$ & 10 \\
\hline $\mathrm{sTfR}(\mathrm{mg} / \mathrm{l}) \ddagger$ & 70 & & $6 \cdot 4$ & $5 \cdot 9,6 \cdot 9$ \\
\hline $\mathrm{SF}(\mu \mathrm{g} / l) \ddagger, \S$ & 70 & & $13 \cdot 7$ & $11 \cdot 2,16 \cdot 6$ \\
\hline Body Fe (mg/kg body weight)‡,§ & 70 & & -0.9 & $-1 \cdot 9,0 \cdot 1$ \\
\hline Anaemia & 34 & $48 \cdot 6$ & & \\
\hline \multicolumn{5}{|l|}{ Fe deficiency } \\
\hline $\mathrm{SF}<12 \mu \mathrm{g} / \mathrm{l}$ & 31 & $44 \cdot 3$ & & \\
\hline $\mathrm{sTfR}>8.3 \mathrm{mg} / \mathrm{l}$ & 12 & $17 \cdot 1$ & & \\
\hline Fe-deficiency anaemiall & 17 & $24 \cdot 3$ & & \\
\hline $\mathrm{CRP}>5 \mathrm{mg} / \mathrm{l}$ & 24 & $34 \cdot 3$ & & \\
\hline
\end{tabular}

WAZ, weight-for-age Z-score; HAZ, height-for-age Z-score; WHZ, weight-for-height Z-score; sTfR, serum transferrin receptor; $\mathrm{SF}$, serum ferritin; CRP, C-reactive protein.

tUnderweight, stunting and wasting defined respectively as WAZ, HAZ and WHZ $<-2$.

†Geometric mean $(95 \% \mathrm{Cl})$.

§Adjusted for elevated CRP $>5 \mathrm{mg} / \mathrm{I}^{(35)}$.

IIDefined as concurrent anaemia and Fe deficiency (SF $<12 \mu \mathrm{g} / \mathrm{l}$ or sTfR $>8 \cdot 3 \mathrm{mg} / \mathrm{l}$ ).

Fe status of the children. The food consumption data show a deficit in energy and Fe intakes. Prevalence of stunting was higher than the national prevalence ${ }^{(37)}$, which is reflective of a process of failure to reach linear growth potential. This could be a result of suboptimal health and/or food and feeding conditions combined with poor household socio-economic conditions indicating the high risk of $\mathrm{ID}^{(5)}$. The anaemia prevalence was high in the present study and half of the children with anaemia had Fe-deficiency anaemia (24.3\%). It is likely that other causes such as presence of illnesses and parasite infestations, inaccessibility of health-care services, genetic determinants and environmental factors ${ }^{(1,38)}$ contributed to the high prevalence of anaemia.

The present study had several methodological strengths and limitations. The two surveys were conducted in the same area and the dietary diversity was found to be similar in both the first and second survey, with a low intake of Fe-rich food by this age group. This similarity must be interpreted with caution however, as intake data in the two surveys had been collected using different methods. Furthermore, the sample size calculations in the second survey were powered for data on children aged 12-59 months, while we analysed data from only a sub-sample of children aged 12-23 months in the present study. Nevertheless, we assumed that the time interval and methodology would not significantly affect our interpretation of results in the simulation.
A quantitative repeated $24 \mathrm{~h}$ recall which has been shown to give acceptable estimates of total intake in rural Kenya was used to collect information on food consumption $^{(39)}$. The method was considered appropriate since it indicates the habitual intake and gives a valid measure of food intake in a population ${ }^{(40)}$. The full probability approach was used to estimate the prevalence of inadequate $\mathrm{Fe}$ intake in a given intake range, as the Fe requirements of children are not normally distributed ${ }^{(21)}$. The observed Fe intake was adjusted for day-to-day variation, which is appropriate for use in analyses of the prevalence of inadequate or excess intakes in the group although it does not address problems of systematic bias due to under-reporting of intakes on the recall days or errors in estimation of nutrient intakes ${ }^{(20)}$. A qualitative $24 \mathrm{~h}$ recall used in the second survey was preferred above list recall as it allows respondents to freely recall all meals and snacks eaten both at home and outside by the child, thus reducing over- or under-reporting of foods consumed $^{(41)}$. We did not collect quantitative breast milk intakes and so our estimates of daily Fe intake for breastfeeding children may be slightly underestimated. In infants fed on breast milk however, over $90 \%$ of their Fe requirements should be met by complementary feeding as early as during the second 6 months of life in order to prevent ID. Although breast milk is known to have a high bioavailability of up to $34 \%^{(42)}$, its Fe concentration has also been shown to decrease drastically by the fifth month 
Table 3 Simulated impact of amaranth-enriched and MNP-fortified maize porridges on iron intake and status in children aged 12-23 months, Mwingi District, Kenya,

\begin{tabular}{|c|c|c|c|c|c|c|c|c|c|c|c|c|}
\hline & \multicolumn{12}{|c|}{ Simulated effect } \\
\hline & \multicolumn{3}{|c|}{ Baselinet } & \multicolumn{3}{|c|}{$\mathrm{MM} \ddagger$} & \multicolumn{3}{|c|}{ MA§ } & \multicolumn{3}{|c|}{$\mathrm{MM}+\|$} \\
\hline & Median & & P25, P75 & Median & & P25, P75 & Median & & P25, P75 & Median & & P25, P75 \\
\hline \multirow{7}{*}{ 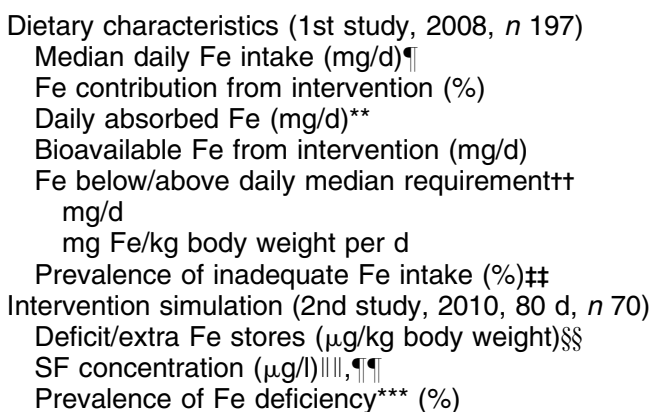 } & & 0 & & & 43 & & $17 \cdot 6$ & 72 & $16 \cdot 4,18 \cdot 7$ & & 56 & $10 \cdot 0,12 \cdot 3$ \\
\hline & \multirow[t]{2}{*}{0.24} & & $0.19,0.31$ & 0.39 & & $0 \cdot 31,0 \cdot 45$ & 0.64 & 12 & $0.58,0.70$ & \multirow{2}{*}{0.57} & \multirow{2}{*}{\multicolumn{2}{|c|}{$0.33^{0.51,0.63}$}} \\
\hline & & 0 & & & \multicolumn{2}{|c|}{$0.15^{0.31,0.45}$} & \multicolumn{3}{|c|}{0.40} & & & \\
\hline & \multirow{2}{*}{$\begin{array}{l}-0.22 \\
-0.016\end{array}$} & & $\begin{array}{l}-0.27,-0.15 \\
-0.02,-0.01\end{array}$ & -0.07 & & $-0.12,-0.01$ & $0 \cdot 18$ & & $0 \cdot 12,0 \cdot 24$ & $0 \cdot 11$ & & $0.05,0.17$ \\
\hline & & \multicolumn{2}{|c|}{$93^{-0.02,-0.01}$} & \multirow{2}{*}{\multicolumn{3}{|c|}{-421}} & \multicolumn{3}{|r|}{$0.01,0.02$} & \multicolumn{3}{|c|}{45} \\
\hline & \multicolumn{3}{|c|}{0} & & & & \multicolumn{3}{|c|}{1083} & \multicolumn{3}{|c|}{662} \\
\hline & $13 \cdot 8$ & & $11 \cdot 3,16 \cdot 8$ & $9 \cdot 5$ & $58 \cdot 6$ & $7 \cdot 0,12 \cdot 6$ & $18 \cdot 8^{*}$ & $27 \cdot 1$ & $16 \cdot 2,21 \cdot 9$ & $18 \cdot 6^{*}$ & $27 \cdot 1$ & $16 \cdot 0,21 \cdot 7$ \\
\hline
\end{tabular}

MNP, micronutrient powder; P25, 25th percentile; P75, 75th percentile; SF, serum ferritin.

Data are median (P25, P75) unless otherwise indicated.

* Significant difference compared with maize porridge-only group: $P<0.05$

This is the existing situation before simulation and the data form the basis of the simulation by assuming that these children did not receive any intervention. Bioavailability of Fe from the diet considered to be $5 \%$ (1). IMM: plain maize porridge with $60 \mathrm{~g}$ of maize flour ( $\mathrm{Fe}$ content $=0.061 \mathrm{~g} / \mathrm{kg}$ wet weight) with $4 \%$ bioavailability $(27)$

SMA: amaranth-maize porridge with $56 \mathrm{~g}$ of grain amaranth flour ( $\mathrm{Fe}$ content $=0.20 \mathrm{~g} / \mathrm{kg}$ wet weight) and $24 \mathrm{~g}$ of maize flour. Assumed bioavailability of amaranth is $3 \%{ }^{(15)}$ and $4 \%$ bioavailability for $\mathrm{Fe}$ in maize $\mathrm{e}^{(27)}$. IMM+: plain maize porridge $\left(60 \mathrm{~g}\right.$ of maize flour) with added $2.5 \mathrm{mg}$ of $\mathrm{Fe}$ in the form of $\mathrm{NaFeEDTA}{ }^{(24)}$. Assumed bioavailability of $\mathrm{Fe}$ in the form of $\mathrm{NaFeEDTA}$ is $7 \%$ (28) and $4 \%$ bioavailability for $\mathrm{Fe}$ in maize ${ }^{(27)}$. -This is the usual $\mathrm{Fe}$ intake from other foods $(4.9 \mathrm{mg} / \mathrm{d})$ plus the added Fe intake from the intervention. Usual $\mathrm{Fe}$ intake has been adjusted for day-to-day variation

${ }^{\star *}$ For the interventions we add the extra absorbable Fe calculated using the intervention respective bioavailability (see footnotes $\ddagger$, $\$$ and $\|$ above) to the usual bioavailable Fe intake calculated using $5 \%$ bioavailability. ++Median absolute requirements for absorbed Fe estimated at $0.46 \mathrm{mg} / \mathrm{d}$ for a child aged $1-3$ years; equivalent to $34.6 \mu \mathrm{g} \mathrm{Fe} / \mathrm{kg}$ body weight per $\mathrm{d}$ for a child aged $1-3$ years weighing $13.3 \mathrm{~kg}$

fłSimulation based on median absorbable Fe intake from the first survey food consumption study and addition of the simulated extra intake of absorbable Fe assuming an $80 \mathrm{~d}$ intervention.

\$Body Fe stores after the $80 \mathrm{~d}$ intervention assuming that the amaranth-enriched and MNP-fortified porridge will provide an extra 0.013 and $0.008 \mathrm{mg}$ Fe/ $\mathrm{kg}$ body weight per $\mathrm{d}$, respectively, while the maize porridge

group would have a deficit of $0.005 \mathrm{mg} \mathrm{Fe} / \mathrm{kg}$ body weight per d obtained after deducting the daily median requirement of $0.0346 \mathrm{mg} \mathrm{Fe} / \mathrm{kg}$ body weight per d.
IIISF from intervention calculated using the Hallberg equation: $Y=9380 X-11260$, where $Y$ is Fe stores expressed as $\mu \mathrm{g}$ Fe/kg body weight and $X$ is log SF$F^{(31)}$.

- Data are geometric mean $(95 \% \mathrm{Cl})$.

${ }^{* * *}$ Based on the simulated SF concentration, defined as $\mathrm{SF}<12 \mu \mathrm{g} / \mathrm{l}$. Baseline prevalence is the actual prevalence as measured in the second survey based on biochemical parameters. 
of lactation by up to $0.3 \mathrm{mg} / \mathrm{l}^{(43)}$. Considering that the age of our study children was above 12 months and a reported minimal breast-feeding, we therefore suppose that the fraction of Fe from breast milk is even lower for our study group and the impact on the estimated $\mathrm{Fe}$ intakes and status is minimal.

The projected values for prevalence of inadequate Fe intake could be attributed to the assumptions that were made. We used a deterministic approach and the model may result in overestimations of the intake distribution as it does not take into account the uncertainties or variability in concentration or consumption data ${ }^{(44)}$. Nevertheless, this model was thought to adequately estimate the expected impact of an intervention to improve dietary $\mathrm{Fe}$ intake in this population. The equation used to estimate SF concentrations has been suggested to effectively predict the effects of Fe fortification under different conditions with respect to dietary properties and $\mathrm{Fe}$ requirements, as it does not overestimate the amount of $\mathrm{Fe}$ stores ${ }^{(31)}$. Evidence has shown that Fe stores tend to be stable or have small changes once the maximum requirement has been reached since the body auto-regulates further Fe absorption ${ }^{(31)}$. The simulated intervention period in the present study was within a time frame that Fe stores would be expected to improve in the majority of the children, as their baseline Fe stores were not high.

We took a conservative bioavailability estimate of $3-4 \%$ for both the amaranth-enriched and plain maize porridge, although the range of bioavailability of non-haem Fe has been reported as $4-12 \%$ in the literature ${ }^{(1)}$. Fe absorption is reduced by high intakes of phytate, which is known to inhibit absorption by forming insoluble Fe-phytate complexes, and the effect has been shown to be dose dependent, starting at very low concentrations of $2-10 \mathrm{mg}$ phytate/meal ${ }^{(45)}$. Our preliminary results (CW MachariaMutie, AM Mwangi and ID Brouwer, unpublished results) indicate that while grain amaranth contains high amounts of $\mathrm{Fe}$, the phytic acid content is also high $(9.6 \mathrm{~g} / \mathrm{kg})$, resulting in a phytate:Fe molar ratio of 3:1 which is still within the inhibitory range ${ }^{(45)}$. The high phytic acid concentration may therefore negatively affect $\mathrm{Fe}$ absorption even when the Fe intakes are increased, especially in the amaranth-enriched porridge group.

From an assumed linear relationship between Fe intake and status our simulated effects may suggest considerable improvement. However, the effects of absorbable Fe in real-life interventions may vary due to other factors that may be either internal/physiological or external ${ }^{(38)}$. The presence of other micronutrients in the MNP which were not accounted for in the simulation and are thought to have a role in anaemia, particularly vitamin $\mathrm{A}^{(46)}$, vitamin $\mathrm{B}_{12}$ and folic acid ${ }^{(47)}$, may also contribute to an increased effect in the MNP group. In the present study we simulated an increment in SF concentration of $4.8 \mu \mathrm{g} / 1$ in the MNP group and $5.0 \mu \mathrm{g} / \mathrm{l}$ in the amaranth group.
A study in South Africa among primary-school children showed an increment in SF concentration of $3 \cdot 1 \mu \mathrm{g} / 1$ between baseline and post-intervention in the treatment group fed with MNP-fortified porridge after 6 months of intervention $^{(48)}$, while an increment of $>10 \mu \mathrm{g} / \mathrm{l}$ in SF concentration was observed in another study in India ${ }^{(12)}$. These varied observations in relation to the simulation could be due to different $\mathrm{Fe}$ requirements according to age group and the presence of infections and de-worming, thus reducing Fe loss due to parasitic infections ${ }^{(1)}$.

\section{Conclusions}

Our results suggest that addition of grain amaranth or MNP to existing maize meal porridges could increase Fe intake adequacy and decrease ID among children in rural Kenya. Validation of such simulations against actual impact on Fe status indicators is needed. However, when resources to do extensive intervention studies are limited, such theoretical simulations may guide the choice of appropriate interventions in the case of policy decisions.

\section{Acknowledgements}

Sources of funding: This work was supported by Clive West Micronutrient Fund, Foundation Van Dam Nutrition Plan and the Nestle Foundation. Conflicts of interest: The authors declare to have no competing interests. Authors' contributions: C.W.M.-M., A.M.M. and I.D.B. designed the research; C.W.M.-M., A.M.O. and J.M.M conducted the research; C.W.M.-M. and I.D.B refined the methodologies; C.W.M.-M. wrote the first draft of the manuscript; all authors read and approved the final manuscript. Acknowledgements: The authors thank the children and parents/caregivers who willingly participated in the study, and also the study field assistants who diligently collected the data.

\section{References}

1. Zimmermann MB \& Hurrell RF (2007) Nutritional iron deficiency. Lancet 370, 511-520.

2. McLean E, Cogswell M, Egli I et al. (2009) Worldwide prevalence of anaemia, WHO Vitamin and Mineral Nutrition Information System, 1993-2005. Public Health Nutr 12, 444-454.

3. Cook JD (1999) Defining optimal body iron. Proc Nutr Soc 58, 489-495.

4. Mwaniki DL, Omwega AM, Muniu EM et al. (1999) Anaemia and Micronutrient Status of Iron, Vitamin A and Zinc in Kenya; National Micronutrient Survey Report. Nairobi: Ministry of Health/KEMRI/University of Nairobi/ SOMANET/UNICEF.

5. Black RE, Allen LH, Bhutta ZA et al. (2008) Maternal and child under-nutrition: global and regional exposures and health consequences. Lancet 371, 243-260. 
6. Grillenberger M (2006) Impact of animal source foods on growth, morbidity and iron bioavailability in Kenyan school children. PhD Thesis, Wageningen University.

7. Macharia-Mutie CW, Brouwer ID, Mwangi AM et al. (2010) Complementary feeding practices and dietary intake among children 12-23 months in Mwingi district, Kenya. Int J Food Safety Nutr Public Health 3, $45-56$.

8. Gegios A, Rachel A, Busie M-D et al. (2010) Children consuming cassava as a staple food are at risk for inadequate zinc, iron, and vitamin A intake. Plant Foods Hum Nutr 65, 64-70.

9. Ndiku M, Jaceldo K \& Sabate J (2010) Dietary patterns of infants and pre-school children in Mwingi and Makueni districts of Ukambani region, Eastern Kenya. Afr J Food Agric Nutr Dev 10, 2804-2817.

10. Johns T \& Sthapit BR (2004) Bio-cultural diversity in the sustainability of developing country food systems. Food Nutr Bull 25, 143-155.

11. Osei AK, Rosenberg IH, Houser RF et al. (2010) Community-level micronutrient fortification of school lunch meals improved vitamin A, folate and iron status of schoolchildren in Himalayan villages of India. J Nutr 140, 1146-1154.

12. Varma JL, Das S, Sankar R et al. (2007) Community-level micronutrient fortification of a food supplement in India: a controlled trial in preschool children aged 36-66 months. Am J Clin Nutr 85, 1127-1133.

13. Lundeen E, Schueth T, Toktobaev N et al. (2010) Daily use of Sprinkles micronutrient powder for 2 months reduces anaemia among children 6 to 36 months of age in the Kyrgyz Republic: a cluster-randomized trial. Food Nutr Bull 31, 446-460.

14. Pedersen B, Kalinowski LS \& Eggum BO (1987) The nutritive value of amaranth grain (Amaranthus caudatus). Plant Foods Hum Nutr 36, 309-324.

15. Ologunde MO, Morris JB, Shepard RL et al. (1994) Bioavailability to rats of iron from fortified grain amaranth. Plant Foods Hum Nutr 45, 191-201.

16. Arsenault JE, Yakes EA, Hossain MB et al. (2010) The current high prevalence of dietary zinc inadequacy among children and women in rural Bangladesh could be substantially ameliorated by zinc bio-fortification of rice. J Nutr 140, 1683-1690.

17. Denova-Gutiérrez E, García-Guerra A, Flores-Aldana M et al. (2008) Simulation model of the impact of biofortification on the absorption of adequate amounts of zinc and iron among Mexican women and preschool children. Food Nutr Bull 29, 203-212.

18. Gibson RS \& Ferguson EL (2008) An Interactive 24-Hour Recall for Assessing the Adequacy of Iron and Zinc Intakes in Developing Countries. Harvest-Plus Technical Monograph Series no 8. Washington, DC and Cali: IFPRI and CIAT.

19. Cogill B (2003) Anthropometric indicators measurement guide. http://www.fantaproject.org/downloads/pdfs/anthro_ 2003.pdf (accessed November 2011).

20. Institute of Medicine (2000) Dietary Reference Intakes: Applications in Dietary Planning. A Report of the Subcommittee on Interpretation and Uses of Dietary Reference Intakes and the Standing Committee on the Scientific Evaluation of Dietary Reference Intakes. Washington, DC: National Academies Press.

21. Allen L, de Benoist B, Dary O et al. (2006) Guidelines on Food Fortification with Micronutrients. Geneva: WHO and FAO.

22. Food and Agriculture Organization of the United Nations (2001) Human Energy Requirements: A Report of a Joint FAO/WHO/UNU Expert Consultation. Food and Nutrition Technical Report Series no. 1. Rome: FAO.
23. Food and Agriculture Organization of the United Nations (2007) Guidelines for Measuring Household and Individual Dietary Diversity. Rome: FAO, Nutrition and Consumer Protection Division.

24. de Pee S, Kraemer K, van den Briel T et al. (2008) Quality criteria for micronutrient powder products: report of a meeting organized by the World Food Programme and Sprinkles Global Health Initiative. Food Nutr Bull 29, 232-241.

25. Ndemwa P, Klotz CL, Mwaniki D et al. (2011) Relationship of the availability of micronutrient powder with iron status and haemoglobin among women and children in the Kakuma refugee camp, Kenya. Food Nutr Bull 32, 286-291.

26. Macharia-Mutie CW, Van de Wiel AM, Moreno-Londono AM et al. (2011) Sensory acceptability and factors predicting the consumption of grain amaranth in Kenya. Ecol Food Nutr 50, 375-392.

27. Cook JD, Reddv MB, Burri J et al. (1997) The influence of different cereal grains on iron absorption from infant cereal foods. Am J Clin Nutr 65, 964-969.

28. Troesch B, Egli I, Zeder C et al. (2009) Optimization of a phytase-containing micronutrient powder with low amounts of highly bioavailable iron for in-home fortification of complementary foods. Am J Clin Nutr 89, 539-544.

29. Christofides A, Asante K, Schauer C et al. (2006) Multimicronutrient Sprinkles including a low dose of iron provided as microencapsulated ferrous fumarate improves haematologic indices in anaemic children: a randomized clinical trial. Matern Child Nutr 2, 169-180.

30. Food and Agriculture Organization of the United Nations \& World Health Organization (2004) Vitamin and Mineral Requirements in Human Nutrition: A Report of a Joint FAO/WHO Expert Consultation, Bangkok, Thailand, 21-30 September 1998, 2nd ed. Geneva: WHO.

31. Hallberg L, Hulthen L \& Garby L (1998) Iron stores in man in relation to diet and iron requirements. Eur J Clin Nutr 52, 623-631.

32. World Health Organization (2001) Iron Deficiency Anaemia: Assessment, Prevention and Control: A Guide for Programme Managers. Geneva: WHO.

33. Cook JD, Flowers CH \& Skikne BS (2003) The quantitative assessment of body iron. Blood 101, 3359-3363.

34. Pfeiffer CM, Cook JD, Mei Z et al. (2007) Evaluation of an automated soluble transferrin receptor (sTfR) assay on the Roche Hitachi analyzer and its comparison to two ELISA assays. Clin Chim Acta 382, 112-116.

35. Thurnham D, McCabe L, Haldar S et al. (2010) Adjusting plasma ferritin concentrations to remove the effects of subclinical inflammation in the assessment of iron deficiency: a meta-analysis. Am J Clin Nutr 93, 546-555.

36. de Onis M, Garza C, Onyango AW et al. (2007) Comparison of the WHO child growth standards and the CDC 2000 growth charts. J Nutr 137, 144-148.

37. Kenya National Bureau of Statistics \& ICF Macro (2010) Kenya Demographic and Health Survey 2008-2009. Calverton, MD: KNBS and ICF Macro.

38. Zimmermann M, Harrington M, Villalpando S et al. (2010) Nonheme-iron absorption in first degree relatives is highly correlated: a stable isotope study in mother-child pairs. Am J Clin Nutr 91, 802-807.

39. Murphy SP, Gewa C, Liang L-J et al. (2003) School snacks containing animal source foods improve dietary quality for children in rural Kenya. J Nutr 133, 11 Suppl. 2, 3950S-3956s.

40. Gibson RS (2005) Principles of Nutritional Assessment, 2nd ed. New York: Oxford University Press.

41. Kennedy G, Pedro M, Seghieri C et al. (2007) Dietary diversity score is a useful indicator of micronutrient intake in non-breast-feeding Filipino children. $J$ Nutr 137, $472-477$. 
42. Dube K, Schwartz J, Mueller MJ et al. (2010) Iron intake and iron status in breastfed infants during the first year of life. Clin Nutr 29, 773-778.

43. Siimes MA, Vuori E \& Kuitunen P (1979) Breast milk iron; a declining concentration during the course of lactation. Acta Paediatr Scand 68, 29-31.

44. Verkaik-Kloosterman J, van't Veer P \& Ocke MC (2009) Simulation model accurately estimates total dietary iodine intake. J Nutr 139, 1419-1425.

45. Hurrell R \& Egli I (2010) Iron bioavailability and dietary reference values. Am J Clin Nutr 91, issue 5, 1461S-1467S.
46. Semba R \& Bloem M (2002) The anaemia of vitamin A deficiency: epidemiology and pathogenesis. Eur J Clin Nutr 56, 271-281.

47. Fishman SM, Christian P \& West KP (2000) The role of vitamins in the prevention and control of anaemia. Public Health Nutr 3, 125-150.

48. Troesch B, van Stuijvenberg ME, Smuts CM et al. (2011) A micronutrient powder with low doses of highly absorbable iron and zinc reduces iron and zinc deficiency and improves weight-for-age Z-scores in South African children. J Nutr 141, 237-242. 